\title{
TURÁN TYPE INEQUALITIES FOR GENERAL BESSEL FUNCTIONS
}

\author{
ÁrpÁd BARICZ, SAMinATHAN PONNUSAMY AND SANJEEV Singh
}

Abstract. In this paper some Turán type inequalities for the general Bessel function, monotonicity and bounds for its logarithmic derivative are derived. Moreover we find the series representation and the relative extrema of the Turánian of general Bessel functions. The key tools in the proofs are the recurrence relations together with some asymptotic relations for Bessel functions.

Mathematics subject classification (2010): 39B62, 33C10, 42A05.

Keywords and phrases: General Bessel functions, Bessel functions of the first and second kind, Turán type inequalities, recurrence relations, asymptotic relations.

\section{REFERENCES}

[1] Á. BARICZ, Bounds for Turánians of modified Bessel functions, Expo. Math. 23, 2 (2015), $223-251$.

[2] Á. BARICZ, Turán type inequalities for regular Coulomb wave functions, J. Math. Anal. Appl. 430, 1 (2015), 166-180.

[3] Á. BARICZ And T. K. PogÁny Turán determinants of Bessel functions, Forum Math. 26, (2014), 295-322.

[4] Á. Elbert And P. D. Siafarikas, On the zeros of $\alpha C_{v}(x)+x C_{v}^{\prime}(x)$, where $C_{v}(x)$ is a cylinder function, J. Math. Anal. Appl. 164, (1992), 21-33.

[5] C. M. Joshi And S. K. Bissu, Some inequalities of Bessel and modified Bessel functions, J. Aust. Math. Soc. Ser. A 50, (1991), 333-342.

[6] A. LAforgia, Inequalities for Bessel functions, J. Comput. Appl. Math. 15, (1986), 75-81.

[7] S. K. LaKshmana RaO, On the relative extrema of the Turán expression for Bessel functions, Proc. Indian Acad. Sci. Sect. A 53, (1961), 239-243.

[8] L. LAndAU, Monotonicity and bounds on Bessel functions, Electron. J. Differ. Equ. Conf. 4, (2000), 147-154.

[9] L. LORCH, Turánians and Wronskians for the zeros of Bessel functions, SIAM J. Math. Anal. 11, (1980), 223-227.

[10] F. W. J. Olver, D. W. Lozier, R. F. Boisvert and C. W. Clark (Eds.), NiST Handbook of Mathematical Functions, Cambridge Univ. Press, Cambridge, 2010.

[11] D. K. Ross, Inequalities and identities for $y_{n}^{2}-y_{n-1} y_{n+1}$, Aequationes Math. 20, (1980), $23-32$.

[12] R. Spigler, Sulle radici dell'equazione, $A C_{v}(x)+B x C_{v}^{\prime}(x)$, Atti Sem. Mat. Fis. Univ. Modena 27, (1978), 153-166.

[13] O. SzÁsz, Identities and inequalities concerning orthogonal polynomials and Bessel functions, J. Analyse Math. 1, (1951), 116-134.

[14] G. N. Watson, A Treatise on the Theory of Bessel Functions, Cambridge University Press, Cambridge, 1922. 